\title{
Peran MDTA dalam Implementasi Pendidikan Agama Islam pada Masa Covid-19 di Yayasan Al Yahdi Kelurahan Tanjung Gusta Kec. Medan Helvetia
}

\author{
Adha Shafira $^{1 *}$, Azzahra Madinatul Syaidah², Nabila Husna Tamara ${ }^{3}$, \\ Khatibah $^{4}$ \\ ${ }^{1}$ Universitas Islam Negeri Sumatera Utara Medan, Indonesia \\ ${ }^{2}$ Universitas Islam Negeri Sumatera Utara Medan, Indonesia \\ ${ }^{3}$ Universitas Islam Negeri Sumatera Utara Medan, Indonesia \\ ${ }^{4}$ Universitas Islam Negeri Sumatera Utara Medan, Indonesia \\ * Corresponding Author. E-mail: ${ }^{1}$ adhashafiraa21@gmail.com
}

\begin{abstract}
Abstrak
Kemajuan suatu bangsa dapat dicapai melalui penataan pendidikan yang baik. Pendidikan agama tidak boleh terlepas dari setiap unsur kehidupan manusia. Munculnya pandemic covid19 di Indonesia berpengaruh terhadap pendidikan. Peran sekolah agama seperti Madrasah Diniyah Takmiliyah Awaliyah (MDTA) sangat bermanfaat sebagai wadah untuk melahirkan generasi yang berkualitas agama yang baik dan berakhlak mulia. Penelitian ini bertujuan untuk mengkaji bagaimana peran MDTA dalam implementasi pendidikan agama Islam selama masa pandemi covid-19 pada yayasan Al-Yahdi kelurahan Tanjung Gusta kecamatan Medan Helvetia. Penelitian ini menggunakana metode kualitatif dengan pendekatan deskriptif. Hasil penelitian ini menunjukkan bahwa Madrasah Diniyah Takmiliyah Awaliyah (MDTA) sangat berperan penting dalam menjalankan pendidikan agama Islam selama masa pandemi di mana dalam implementasinya yayasan Al-Yahdi tetap menjalankan proses pembelajaran secara klasikal atau tatap muka dengan mengikuti protokol kesehatan dan mengurangi jam belajar hal tersebut dilakukan demi tercapainya tujuan pendidikan agama Islam.
\end{abstract}

Kata Kunci: MDTA, Pandemi Covid-19, Pendidkan Agama Islam.

The Role of MDTA in the Implementation of Islamic Religious Education during the Covid19 Period at the Al Yahdi Foundation, Tanjung Gusta Village, Kec. Helvetia Field

\begin{abstract}
The progress of a nation can be achieved through the arrangement of good education. Religious education cannot be separated from every element of human life. The emergence of the COVID-19 pandemic in Indonesia has an impact on education. The role of religious schools such as Madrasah Diniyah Takmiliyah Awaliyah (MDTA) is very useful as a forum to give birth to a generation of good religious quality and noble character. This study aims to examine how the role of MDTA in the implementation of Islamic religious education during the COVID-19 pandemic at the Al-Yahdi Foundation, Tanjung Gusta sub-district, Medan
\end{abstract}


Helvetia sub-district. This study uses a qualitative method with a descriptive approach. The results of this study indicate that Madrasah Diniyah Takmiliyah Awaliyah (MDTA) plays an important role in carrying out Islamic religious education during the pandemic where in its implementation the Al-Yahdi foundation continues to carry out the classical or face-to-face learning process by following health protocols and reducing learning hours. in order to achieve the goals of Islamic religious education.

Keywords: MDTA, Covid-19 Pandemic, Islamic Religious Education.

\section{Pendahuluan}

Munculnya pandemi covid- 19 telah menciptakan tantangan baru dalam seluruh aspek kehidupan hampir di seluruh dunia. Wabah Covid-19 di Indonesia berimbas pada beberapa aspek kehidupan, mulai dari aspek sosial, ekonomi, kehidupan beragama, bahkan sampai kepada aspek pendidikan (Ritonga et al., 2020). Salah satu dampaknya ialah dalam dunia pendidikan agama Islam. Pendidikan Islam yang telah berlangsung menjadi bagian yang tidak terpisahkan dari sistem pendidikan nasional juga mengalami dampak dari hal tersebut. Pendidikan Islam memiliki standard dasar pada kehidupan yaitu sebuah pembiasaan dalam menjalankan aktivitas sehari-hari. Ini menjadi hal yang sangat penting bagi anak dan peserta didik, misalnya anak mengetahui bagaimana cara beriman dan bertaqwa kepada Tuhan, berahlak mulia, kreatif, mandiri, dan memiliki rasa bertanggungjawab, dan lainnya.

Salah satu kebijakan baru yang terlihat jelas dan berlaku untuk semua jenjang pendidikan adalah terkait perubahan sistem pembelajaran yang lazimnya atau lebih seringnya dilakukan di dalam ruangan atau kelas berubah menjadi cukup di rumah saja. Kebijakan untuk tetap di rumah saja, selalu menjaga jarak dan menghidari kerumunan di mana pun dan kapan pun harus diikuti dengan perubahan sistem pembelajaran tatap muka menjadi sistem pembelajaran daring (online).

Pembelajaran daring merupakan model pembelajaran berbasis teknologi melalui pembelajaran jarak jauh dengan menggunakan fasilitas jaringan internet untuk dapat berinteraksi secara daring.
Berbagai elemen telah berupaya untuk ikut serta dalam mengatasi dan mencegah penyebaran Covid-19, baik pemerintah maupun seluruh lapisan masyarakat. Pada sektor pendidikan berupaya dengan mengeluarkan kebijakan tentang pembelajaran secara daring dan bekerja dari rumah dalam rangka mencegah penyebaran Covid-19 (Kemendikbud, 2020).

Dalam pelaksanaanya di lapangan tentu mengalami banyak tantangan/ problematika dimana pada umumnya pembelajaran daring sulit diterapkan pada anak-anak yang usianya masih 4-12 tahun atau setara dengan PAUD, TK, SD, karena di usia tersebut mereka memerlukan yang namanya bimbingan ketika menjalani pendidikan oleh karena keterbatasan kemampuan tersebut maka pembelajaran daring tidak berjalan dengan efektif.

Pada dasarnya, keberhasilan pendidikan agama Islam dapat terwujud apabila seluruh aspek yang berhubungan langsung dengan pendidikan dapat bekerja sama dan saling membantu dari berbagai pikak antara lain pihak sekolah dengan orang tua peserta didik, lembaga dengan masyarakat dan lain sebagainya, demi meningkatkan keberhasilan pendidikan agama Islam.

Sebelum lahirnya Undang-Undang Nomor 20, Tahun 2003 tentang Sistem Pendidikan Nasional (UU 20/2003), madrasah diniyah dikenal sebagai madrasah (Daulay, 2007). Menurut Daulay, MDTA berperan dalam melengkapi dan menambah pendidikan agama bagi anak-anak yang sekolah di sekolah-sekolah umum. Perkembangan MDTA dilatar belakangi oleh keresahan sebagian orang tua siswa karena merasakan pendidikan agama di 
sekolah umum kurang memadai dalam mengantarkan anaknya untuk dapat melaksanakan ajaran Islam sesuai dengan yang diharapkan.

Dari kebutuhan masyarakat akan jenis lembaga pendidikan seperti inilah, MDTA tetap bertahan meski adanya pandemi Covid-19. Walaupun hingga saat ini MDTA kurang mendapatkan perhatian khusus dari pemerintah, baik pemenuhan anggaran maupun bantuan ketenagaan, namun peran madrasah diniyah merupakan hal yang sangat penting dalam sistem pendidikan yang harus dipikirkan bersama. MDTA merupakan salah satu lembaga pendidikan keagamaan pada jalur luar sekolah yang secara komprehensif mampu memberikan pendidikan agama Islam kepada anak didik (yang tidak terpenuhi pada jalur sekolah) dan diberikan melalui sistem klasikal atau tatap muka. MDTA umumnya diselenggarakan oleh masyarakat sebagai perwujudan pendidikan dari, oleh, dan untuk masyarakat sendiri oleh karena itu banyak pendirinya ialah mereka yang ingin berperan untuk kemajuan umat.

Dengan melihat pentingnya hal tersebut maka pendidikan agama Islam harus tetap dilakukan meskipun masa pandemic Covid-19 yang terjadi saat ini. Hal inilah yang membuat penulis tertarik untuk melakukan penelitian mengenai peran MDTA (Madrasah Diniyah Takmiliyah Amaliyah) dalam implementasi pendidikan agama Islam pada masa pandemi Covid-19 pada Yayasan Al- Yahdi Kelurahan Tanjung Gusta Kecamatan Medan Helvetia.

\section{Metode}

Metode penelitian adalah cara kerja yang digunakan untuk mengumpulkan data dan kemudian mengolah data sehingga menghasilkan data yang dapat memecahkan permasalahan penelitian. Seperti yang diungkapkan oleh Winarno Surakhmad (1985:151) yaitu: "Metode penelitian merupakan rangkaian yang dipergunakan untuk mencapai suatu tujuan, misalnya untuk menguji serangkaian hipotesis, dengan mempergunakan teknik serta alatalat tertentu".

Pada penelitian ini penulis memakai pendekatan kualitatif dengan metode deskriptif. Pendekatan kualitatif merupakan suatu pendekatan yang dilakukan dengan analisis dan interpretasi teks dan juga interview, adapun tujuannya untuk menemukan makna dari suatu fenomena. Penelitian kualitatif adalah pengumpulan data pada suatu latar alamiah dengan tujuan untuk menafsirkan fenomena yang terjadi dimana peneliti sebagai instrument kunci. Sedangkan metode pada penelitian ini adalah metode deskriptif.

Deskriptif adalah suatu metode dalam penelitian dimana bertujuan untuk meneliti status kelompok manusia, objek, suatu kondisi, suatu sistem pemikiran, ataupun status kelas peristiwa yang terjadi sekarang. Menurut Bogdan dan Taylor penelitian kualitatif adalah suatu prosedur penelitian yang mengahasilkan data deskriptif berupa kata-kata tertulis dan lisan dari orang yang akan diteliti.

\section{Teknik Pengumpulan Data}

Teknik pengumpulan data dalam penelitian ini berupa wawancara siswa, observasi, dan dokumentasi. Kegiatan pengumpulan data diperoleh melalui kegiatan survei lapangan secara langsung.

1. Teknik Wawancara (Interview)

Wawancara adalah percakapan dengan maksud tertentu. Percakapan itu dilakukan oleh dua pihak, yaitu pewawancara (interviewer) yang mengajukan pertanyaan dan terwawancara (interviewee) yang memberikan jawaban atas pertanyaan itu. Teknik ini dilakukan untuk menggali informasi dari narasumber yaitu ketua yayasan, dan guru-guru di MDTA Yayasan Al-Yahdi Medan.

2. Teknik Observasi (Pengamatan)

Observasi adalah pengamatan yang dilakukan secara sengaja, sistematis, mengenai fenomena sosial dengan gejala-gejala psikis untuk kemudian dilakukan pencatatan. Teknik ini dilakukan untuk mengamati 
implementasi pendidikan agama islam MDTA (Madrasah Diniyah Takmiliyah Awaliyah) di Yayasan Al-Yahdi Medan selama masa pandemi covid-19 berlangsung.

\section{Teknik Studi Dokumentasi}

Studi dokumen merupakan catatan peristiwa yang sudah berlalu. Dokumen bisa berbentuk tulisan, gambar, atau karya-karya yang monumental. Teknik ini digunakan untuk memperoleh hasil berupa data siswa beserta kesimpulan yang diperoleh peneliti di lokasi penelitian yaitu Yayasan Al-Yahdi Medan yang berdiri sejak 2009.

\section{Hasil dan Pembahasan}

Berdasarkan hasil observasi dan wawancara yang dilakukan penulis pada 25 Agustus 2021 di MDTA Yayasan AlYahdi yang berlokasi di Jl. Klambir V No. 175 C Gg. Madrasah, Kelurahan Tanjung Gusta Kecamatan Medan Helvetia, dapat disimpulkan bahwa MDTA (Madrasah Diniyah Takmiliyah Awaliyah) sebagai sekolah agama Islam sangat berperan penting dalam implementasi pendidikan agama Islam selama masa pandemi Covid19. Akan tetapi pembelajaran daring (online) dinilai belum efektif dilakukan, oleh karena itu proses pembelajaran masih dilakukan secara klasikal demi mencapai tujuan ketuntasan belajar siswa dalam pembelajaran agama Islam. Masih banyak ditemukan kendala dalam penerapan pembelajaran daring (online) sehingga Yayasan tersebut belum menerapkan pembelajaran daring. Adapun kendalanya dan tantangannya diantaranya.

1. Siswa/i yang belajar agama di MDTA Yayasan Al- Yahdi merupakan anakanak yang dikategorikan kurang mampu dan anak-anak yatim dhuafa. Hal ini dikatakan langsung oleh pendiri yayasan Al- Yahdi yaitu ibu Supina ia mengatakan secara langsung kalau yang boleh menjadi murid di Yayasan tersebut hanyalah orang-orang yang kurang mampu saja dalam arti tujuan berdirinya yayasan tersebut ialah untuk membantu anak-anak yang kurang mampu dan yatim dhuafa untuk tetap mendapatkan pendidikan agama dengan cara meringankan mereka dalam hal biaya pendidikan yang tergolong murah yaitu hanya 10.000 saja per bulannya.

2. Latar belakang berdirinya MDTA (Madrasah Diniyah Takmiliyah Awaliyah ialah untuk memberikan pengajaran agama Islam kepada anakanak kurang mampu dan anak-anak yatim dhuafa oleh karena itu tentu mereka akan kesulitan jika pihak yayasan menekankan untuk menerapkan pendidikan di masa pandemi ini secara daring (online). Untuk mengikuti perkembangan pembelajaran online tentu banyak hal yang harus dipertimbangkan, diantaranya ialah kesiapan pendidik dan peserta didik dari berbagai aspek baik secara psikologis, maupun kesiapan alat berupa teknologi berupa smartphone. Banyak diantara peserta didik di MDTA Al- Yahdi yang kurang dari segi ekonomi tidak dapat dipungkiri pengaruh adanya pandemic covid-19 juga berdampak terhadap penghasilan para orang tua siswa, hal tersebut membuat mereka kesulitan untuk membeli smartphone untuk anak-anak mereka.

3. Faktor usia yang tergolong masih anakanak yang dimana peserta didik yang berkisar 4- 12 tahun masih belum mahir ketika diminta menggunakan smartphone misalnya saja mereka kesulitan menggunakan aplikasi yang mendukung pembelajaran online seperti Zoom, Google meet, Jitsi, WhatsApp, E-Learning, dan aplikasiaplikasi lainnya yang sejenis. Kurangnya pemahaman mereka untuk mengikuti pembelajaran daring (online) menjadi salah satu problematika untuk melaksanakan pembelajaran secara daring. Apabila ingin menerapkan pembelajaran daring otomatis orang tua 
Jurnal Edumaspul, 5 (2), Year 2021 - 5

(Adha Shafira, Azzahra Madinatul Syaidah, Nabila Husna Tamara, Khatibah)

sangat berperan sebagai pembimbing mereka ketika belajar akan tetapi faktanya para orang tua mereka juga kurang mampu dalam hal pengetahuan teknologi karena keterbatasan pengetahuan tersebut para orang tua peserta didik di MDTA Al- Yahdi mengharapkan anak-anaknya untuk mengikuti pembelajaran agama Islam di MDTA tersebut.

Implementasi pendidikan agama Islam di Yayasan Al-Yahdi sesuai dengan hasil observasi yang telah dilakukan di lokasi, peneliti dapat menyimpulkan bahwa pelaksanaan pendidikan agama islam di Yayasan Al-Yahdi masih menggunakan metode klasikal yaitu dengan tatap muka seperti biasa akan tetapi perbedaannya selama masa pandemi seluruh peserta didik, guru, dan pekerja lainnya harus mengikuti protokol kesehatan yang dianjurkan pemerintah saat ini yaitu dengan mencuci tangan, memakai masker, dan menyediakan hand sanitizer. Yayasan sudah mengikuti arahan dari pemerintah seperti menyediakan wastafel cuci tangan di pintu masuk Yayasan, menghimbau untuk menggunakan masker selama proses pembelajaran berlangsung. Adapun peran MDTA dalam implementasi pendidikan agama Islam selama masa pandemi di antaranya.

\section{MDTA (Madrasah Diniyah}

Takmaliyah Awaliyah) merupakan salah satu lembaga pendidikan agama yang berfungsi sebagai wadah untuk melangsungkan proses pembelajaran agama Islam meskipun adanya pandemi, akan tetapi pendidikan agama harus tetap dilaksanakan karena agama tetap harus ditegakkan dan dipelajari demi melahirkan generasi yang berakhlak mulia. Implementasi pendidikan agama di MDTA Al-Yahdi diantaranya melaksanakan pembelajaran dengan materi yang sudah disusun dan di tetapkan di seluruh madrasah di Indonesia, membiasakan peserta didik untuk melaksanakan shalat secara berjamaah, mengajarkan pentingnya untuk menjaga kesehatan, mengajarkan tentang akhlak mulia dan adab-adab dalam Islam, mengajarkan doa-doa dalam Islam, dan masih banyak lainnya.

2. Dalam penerapannya MDTA AlYahdi sangat berperan dalam mengisi waktu kosong para peserta didik agar lebih bermanfaat selama masa pandemi. Seperti yang kita ketahui bahwa semenjak adanya pandemi sekolah menerapkan pembelajaran daring, sehingga anak-anak banyak yang merasa jenuh ketika mereka harus berada di rumah saja. Akan tetapi dengan metode yang masih klasikal di Yayasan Al- Yahdi maka hal ini dapat membuat para peserta didik merasa senang ketika mereka bertemu dengan teman-temannya secara langsung. Dari pada mereka di rumah saja dan tidak melakukan kegiatan yang produktif alangkah baiknya mereka mengikuti pendidikan agama Islam di MDTA.

3. Dalam pelaksanaan pembelajaran agama Islam, MDTA Al- Yahdi tidak hanya mengajarkan mereka tentang pengetahuan agama Islam saja melainkan mengajak mereka untuk kreatif seperti membuat kerajinan dan lain sebagainya. Dengan begitu selama masa pandemi akan meningkatkan imun para peserta didik dengan cara hal-hal yang sederhana yang membuat mereka bahagia dan lebih produktif yaitu dengan belajar mencoba hal baru yang bermanfaat. Pihak yayasan sengaja menyediakan aula untuk mendukung kreatifitas anak-anak di yayasan tersebut dengan begitu peserta didik memiliki wadah khusus untuk mengekpresikan krestifitasnya.

Semenjak adanya pandemi, penerapan pembelajaran di MDTA Al-Yahdi tidak hanya sebatatas pengetahuan saja melainkan juga mengajarkan peserta didik untuk melakukan pola hidup yang sehat. Berdasarkan hasil penelitian, dimana peneliti melihat Yayasan tersebut 
menerapkan kegiatan senam sehat di sore hari bagi para peserta didik dan guru-guru dengan tujuan menjaga kesehatan jasmani dan membangkitkan rasa semangat para peserta didik dan guru yang mengajar di yayasan tersebut.

\section{Simpulan}

Berdasarkan penelitian yang telah dilakukan dengan menggunakan pendekatan kualitatif dengan metode deskriptif dapat diambil kesimpulan bahwa MDTA (Madrasah Diniyah Takmaliyah Awaliyah) di Yayasan Al Yahdi Kelurahan Tanjung Gusta Kecamatan Medan Helvetia sangat berperan penting dalam pendidikan agama Islam di masa pandemi, di mana implementasi MDTA di yayasan Al-Yahdi masih dilakukan secara klasikal atau tatap muka, hal ini dikarenakan berbagai faktor yang menjadi kendala apabila dilakukan pembelajaran secara daring (online) diantaranya latar belakang keluarga para peserta didik yang kurang mampu karena peserta didik di MDTA tersebut merupakan anak-anak yang berasal dari keluarga kurang mampu dan anak-anak yatim dhuafa dengan begitu banyak diantara mereka yang tidak mampu membeli smartphone, kurangnya kemampuan menggunakan teknologi karena faktor umur yang masih butuh bimbingan dari orang tua, para orang tua yang kurang mampu mengikuti perkembangan ilmu teknologi sehingga mereka juga tidak mampu untuk mengajarkan kepada anaknya. Adapun peran MDTA dalam implementasi pendidikan agama Islam selama masa pandemi diantaranya MDTA (Madrasah Diniyah Takmaliyah Awaliyah) merupakan salah satu lembaga pendidikan agama yang berfungsi sebagai wadah untuk melangsungkan proses pembelajaran agama Islam meskipun adanya pandemi akan tetapi pendidikan agama harus tetap di jalankan. Dalam penerapannya MDTA AlYahdi sangat berperan dalam mengisi waktu kosong para peserta didik agar lebih bermanfaat selama masa pandemi, selain itu mereka tidak hanya diajarkan tentang pengetahuan agama Islam saja melainkan mengajak mereka untuk kreatif seperti membuat kerajinan dan lain sebagainya, dan juga mengajarkan mereka untuk senantiasa hidup melakukan pola hidup sehat contohnya dengan melakukan kegiatan senam bersama di sore hari.

\section{Daftar Pustaka}

[1] Achmad, Wahyudi. (2020). Peran dan Tantangan Pendidikan Agama Islam di Era Pandemi Covid-19 pada Lingkungan Keluarga. Journal of Islamic Education, $5(2)$.

https://ejournal.stitmuhbangil.ac.id/index . .php/jie/article/view/188.

[2] Alfianto, Adhika. (2020). Efektivitas Pembelajaran Daring Pada Mata Kuliah Pendidikan Agama Islam dalam Situasi Pandemi Covid-19. Ta'dibuna: Jurnal Pendidikan Agama Islam, 3(2). http://dx.doi.org/10.30659/jpai.3.2.13$\underline{26}$.

[3] Diantoro, Fery. (2021). Upaya Pencapaian Tujuan Pendidikan Islam Dalam Pendidikan Nasional Dimasa Pandemi Covid-19. MA'ALIM: Jurnal Pendidikan Islam, 2(1). https://jurnal.iainponorogo.ac.id/index.p hp/maalim/article/view/3035.

[4] Sabiq, Ahmad Fikri. (2021). Pembelajaran PAI dengan Pendekatan Integratif pada Masa Pandemi Covid-19 di SD PTQ Annida Salatiga. Jurnal Pendidikan dan Pelatihan, 5(1). https://bdksemarang.ejournal.id/Ed/article/view/132.

[5] Qomari, Fikri Aflaha. (2021). Penerapan Pembelajaran Pendidikan Agama Islam di Masa Pandemi Covid-19. An-Nuha: Jurnal Pendidikan Agama Islam, 1(1).

[6] Khairuddin, Arif, et.al. (2019). Implementasi Pendidikan Agama Islam dalam Membentuk Karakter Religius Siswa. Jurnal Pedagogik, 6(1). http://www.riset.unisma.ac.id/index.php/ fai/article/view/3230. 
[7] Abidin. (2021). Upaya Guru PAI Menanggulangi Kemalasan Belajar AlQur'an Siswa SD Selama Masa Pandemi Covid-19 di Kabupaten Blitar. Jurnal Edureligia, $5(1)$. https://plu.mx/plum/a/?doi=10.33650/ed ureligia.v5i1.1604.

[8] Susanti, Wati. (2020). Implementasi Pembelajaran Secara Daring pada Mata Pelajaran Pendidikan Agama Islam Tingkat SMP di Masa Pandemi Covid19. Jurnal Inovasi Pendidikan, 7(2). http://jurnal.umsb.ac.id/index.php/inovas ipendidikan/article/view/2311.

\section{Profil Penulis 1}

Adha Shafira, lahir di Medan, 21 Februari 2000. Pernah menempuh pendidikan di TK YPI Madinatussalam, kemudian melanjutkan pendidikan sekolah dasar di SD YPI Madinatussalam dan lulus pada tahun 2012. Lalu, melanjutkan pendidikan ke jenjang sekolah menengah pertama di SMPN 29 Medan dan lulus pada tahun 2015. Selanjutnya, menempuh pendidikan jenjang sekolah menengah atas di MAN 1 Medan dan lulus pada tahun 2018. Dan sekarang sedang melaksanakan pendidikan di UIN Sumatera Utara Medan di Jurusan Pendidikan IImu Pengetahuan Sosial.

\section{Profil Penulis 2}

Azzahra Madinatul Syaidah, lahir di Medan, 15 Januari 2000. Pernah menempuh pendidikan jenjang sekolah dasar di SDN 060812 tamat pada tahun 2012. Lalu melanjutkan pendidikan jenjang sekolah menengah pertama di SMPN 2 Medan dan lulus pada tahun 2015. Selanjutnya, menempuh pendidikan jenjang sekolah menengah atas di SMAN 2 Medan dan lulus pada tahun 2018. Dan sekarang sedang melaksanakan pendidikan di UIN Sumatera Utara Medan di jurusan Pendidikan IImu Pengetahuan Sosial.

\section{Profil Penulis 3}

Nabilla Husna Tamara, lahir di Medan, 30 Juni 2000. Pernah menempuh pendidikan jenjang sekolah dasar di SD Swasta Islam Teladan dan tamat pada tahun 2012. Lalu melanjutkan pendidikan jenjang sekolah menengah pertama di SMPN 4 Medan dan lulus pada tahun 2015. Selanjutnya, menempuh pendidikan jenjang sekolah menengah atas di SMA Swasta UISU Medan dan lulus pada tahun 2018. Dan sekarang sedang melaksanakan pendidikan di UIN Sumatera Utara Medan di jurusan Pendidikan Ilmu Pengetahuan Sosial.

\section{Profil Penulis 4}

Khatibah merupakan dosen di UIN Sumatera Utara Medan, dan dalam konteks ini, ditugaskan sebagai Dosen Pendamping Lapangan (DPL) mahasiswa KKN 25 tahun 2021. 